\title{
MESEARCH AND THE GOTHIC IMAGINATION
}

\author{
LAURENCE RAW \\ Başkent University, Ankara, Turkey
}

\begin{abstract}
Based on a transformational moment in 2013, this piece calls for a revision in research methods, with the attention focused less on critical objects and more on one's personal response to them. This technique of mesearch, with the self placed at the center of one's agenda, offers unique opportunities for self-analysis through redefining one's relationship to literature. The point is exemplified through a case-study of Mary Shelley's Frankenstein.
\end{abstract}

Keywords: mesearch, adaptation, pedagogy, Gothic fiction

In the autumn of 2013 I underwent an operation that put me off work for over three months and rendered me vocally impaired. Hitherto I had been a fairly extrovert personalityr possessed of a voice that colleagues said could be heard right down the corridor of our departmental building; now I had to adapt to the experience of being unable either to shout or lecture for sustained periods. The task of adjustment was not easy professionally as well as personally: I could no longer act "the sage on the stage," in front of admiring audiences. Such handicaps might seem insignificant but for me it represented a complete change in my public image as a teacher and scholar.

It was during this period of reconstruction that I encountered Emma Rees's article on "The Rise of 'Mesearch" published in the Times Higher Education Supplement in March 2015. She argues both for openness and honesty in academic practice by rethinking the relationship between life-experiences and research. Interviewed in the article, Sonja Boon, advocates the practice of mesearch, more accurately defined as placing the self at the centre of academic research so as to expose " profound silences and erasures in the academy," especially the connection between the self and the questions invoked in one's academic agenda. Rees makes the point: "if 'I' engage in research that impacts on me, and then 'I' go into the classroom, then ' $\mathrm{I}$ ' am engaging in an intricate, tripartite negotiation with myself, with my research, and my undergraduates." Learning should create possibilities - for freedom, for intellectual and personal development, and for life - and thereby promote "an openness of mind and heart 
that allows us to face reality even as we collectively imagine ways to move beyond boundaries, to transgress." Our research acquires transgressive potential, while our pedagogy undergoes similar transformative processes (Rees 4).

Rees's arguments proved especially pertinent for me: was there a way in which I could integrate personal transformations into my own academic work, especially in adaptation studies? I'd already spent two years researching the relationship between adaptation and psychology, based on the insights of Jean Piaget and Jerome Bruner: was there a way I could integrate my discoveries with mesearch? (Raw and Gurr passim). This article explores the possibility by describing my initial training as a literary scholar using Leavisite methods of criticism based on objectivity, impartiality and balance. While such precepts gave my critical efforts a certain respectability in academic circles, they tend to be rather limiting. I seldom felt actively engaged with my graduate research, or the work on Elizabethan drama pursued during my early academic career. Drawing on the art critic Andrew Graham-Dixon's insights, I believe that all academic enterprises should be underpinned by the desire to uncover something new, not only for oneself but for learners as well. The academic should resemble the explorer ploughing through undiscovered territory.

Through a case-study of Mary Shelley's Frankenstein, I will show how this process of discovery learning might work in practice; so that we as readers might have the privilege of experiencing the same exhilaration that Shelley might have experienced when she composed the novella in 1818. Understanding the potential of the Gothic imagination as a potential transformative force offers a series of possibilities for mobilizing mesearch in our research programs.

I began my career as a literature scholar four decades ago when I was taught the rudiments of Practical Criticism. Poetic analyses had to be divided into Content and Form, more commonly defined as "what is said," and "how it is said." Convincing pieces consisted of informing readers what the poet were saying, followed by examples of how they employed linguistic and rhythmical techniques to communicate their meaning. This formalistic approach to poetry analysis was designed to increase our sensitivity to language in which sound assumed as much significance as sense.

Traceable back to I. A. Richards's seminal volume Practical Criticism (1929), this mode of analysis focused attention on "the words on a page" as a means of understanding a poem's currents of emotion and meaning (Richards 77). Such techniques contribute towards what Richards describes as an "organised response" identifying the various currents and helping to clarify our own emotions. The analysis of texts was a moral activity, with readers bringing all of their sensibilities to bear on the analysis of a poem. When I came to the Republic of Turkey in 1989, I found this framework being used by several of my new colleagues in an attempt to set "implicit standards" of speaking and writing that could match anything produced in the West (Raw 92). I remember being 
quite at home with this kind of approach, except for one occasion when I tried to illustrate D. H. Lawrence's dictum from Lady Chatterley's Lover: "Never was an age more sentimental, more devoid of real feeling, more exaggerated in false feeling, than our own" (ch. 3). Lawrence here describes a feeling significantly different from that embraced by Richards: we respond with our body and soul to a stimulus, and if we should experience an extreme reaction, so be it. I quoted the example from my adolescence when I first heard the song from Pinocchio (1940) - "When You Wish upon a Star," written by Leigh Harline and Ned Washington, Sung by Cliff Edwards, the lyrics suggest that wishes can come true so long as children believe in them profoundly. My educator at school told me not to sentimentalise and retain my objective perspective. Memories of that comment haunted my later life: how do I separate objectivity from sentimentality? And why should we pay more attention to Leavis rather than Disney?

I found myself asking different questions. It didn't really matter whether it was a high or a popular cultural text: whenever I read something, I looked for what it could tell me about my life - my past, present, or future. I read John Williams's Stoner (1963), an academic novel whose eponymous hero becomes a teacher so as to understand "the dignity of art." Towards the end of his life, when he has endured many disappointments, he thinks of academe as "the only life that had not betrayed him." He understands that there is a continual battle between the academy and the world at large: the academy must sustain the cultural values that shape the world for as long as possible (Williams 24, 176, 211). Did I feel the same about academe? Did I choose to remain a university teacher out of some quixotic belief that I might influence learners' lives for the better? And did that knowledge help me to understand "the dignity of art?" Gary Shteyngart's autobiographical memoir Little Failure, a story of assimilation and self-actualisation, told me a lot about my relationship to my parents as well as understanding why I had to leave Great Britain for the Republic of Turkey. Reading was not just something pleasurable; it provided me with a series of incentives to pursue mesearch as a way of life.

But how could I integrate this agenda into the day-to-day business of teaching and writing about literature? The answer came quite unexpectedly from a television programme, first broadcast in October and November 2014, when Andrew Graham-Dixon explained how a group of $19^{\text {th }}$ century artists and architects spurned late Georgian values and turned instead to an artistic form (Gothic) that was both backward and forward-looking. In Frankenstein Mary Shelley warns of the dangers posed by science, yet at the same time celebrates the power of the imagination to turn away from quotidian realities and explore innovative possibilities. Such qualities were shared by the Romantics; what distinguishes the Gothic from the Romantic is the search for new constructions of "humanity," or even to reflect ontologically on what "humanity" actually 
represented (The Art of Gothic). Graham-Dixon's arguments struck an answering chord in me as I struggled to adjust to my vocal shortcomings, and took note of Shelley's novella.

Frankenstein contains moments of supreme pleasure; at one point referring to the "sublime ecstasy that gave wings to the soul and allowed it to soar from the obscure world to light" (ch. 10); and the joy filling the heart "which was before sorrowful" (ch. 10). Later on we hear about a soul that "overflowed with ardent affections .... [a] friendship was of that devoted and wondrous nature that the world-minded teach us to look for only in the imagination" (ch. 18). In the subsequent chapter we discover more about "the sight of what is beautiful in nature or the study of what is excellent and sublime in the productions of man," that interest the heart and "communicate elasticity" to the spirits (ch. 19). Even when the Creature is destroyed he looks "nubile and godlike in ruin" (ch. 24); the product of a scientific imagination that was "vivid" and "intense" powers of analysis: "by the union of those qualities I [Frankenstein] conceived the idea and executed the creation of a man." (ch. 24) Even if the experience proves catastrophic in the end, Shelley believes that humankind possesses the potential to transcend the restrictions imposed on them by their cultures and create new opportunities for themselves.

Inspired by Shelley's ideas, I wondered if I could develop a mesearchoriented pedagogy designed to stimulate the collective imagination of myself and my learners. The signs were unpromising - even after two decades working in various institutions the majority of learners still devoted most of their time to the tasks of reading texts and discussing texts. I consulted Robert J. Nash's Liberating Scholarly Writing: The Power of Personal Narrative (2004), that argues for a shift towards autobiography or SPNs (Scholarly Personal Narratives) as a method of approaching literary texts. Rather than writing the typical literary critical essay, Nash focuses on the personal element that at its best can challenge "historical understanding in ways unthinkable even a generation ago." (29) SPNs can be theoretical, historical or practical; selfrevealing yet coherent in their focus on "particular events, people, and critical incidents that frame the writer's life." (30) SPNs have the potential to stimulate the imagination by encouraging writers to offer personal evaluations of classic texts, concentrating on whether their lives have been in any way transformed by the reading of a text. I would participate in a similar activity: what I had learned through my reading of texts such as Stoner reshaped my approach to classwork. In one representative class I asked learners to consider Great Expectations (a popular text for undergraduates studying English Literature), I asked them to imagine a moment of intense loneliness, when they felt that they could not communicate their feelings to anyone. I asked them to remember how they tried to deal with this experience. I subsequently asked them to compare their personal narratives with Pip's experiences as a young boy coping with the stress 
of living with the Gargerys, as well as dealing with Magwitch's unexpected appearance.

Methodologically speaking this activity not only drew on learners' personal experiences but provided the basis for a mesearch-focused framework, with the learner placed at the centre of the interpretive experience. Rather than considering the text in isolation, they are encouraged to assess the extent to which it contributes to their understanding of the worlds they inhabit. As an educator I found this mode of learning quite fascinating. With everyone educator and learners like - learning something about themselves as well as Dickens's world of nineteenth century England.

Although those modes of learning proved revelatory for all of us, it can be criticised on two counts. First, by focusing on the personal rather than the linguistic aspects of the novel, we ran the risk of neglecting its basic themes. Second, we were in danger of taking the novel at face value and thereby overlooking the fact that Great Expectations is "difficult, if not impossible, to fathom fully." (Oord 1) From a mesearch-oriented perspective, it's maybe unnecessary to grasp it fully: one of the pleasures of mesearch is to recognize that while we can never understand ourselves in depth, it might be interesting to contemplate the inexplicable. Interviewed by Psychology Today in July 2008, Peter Brugger said that his entire academic life has been devoted to addressing unanswerable problems: "he sliced into the question of paranormal beliefs to find answers that satisfied him" (qtd. in Webber, 35). Note the use of the pronoun here; the object of research consists of satisfying the researcher, making them feel that what they are doing in personally worthwhile. This is the principal objective of mesearch; to discover answers for oneself and share them with one's peers. Mesearch is eminently scholarly in its willingness to experiment with ideas, as well as building on others' opinions. This is a considerable confidence-builder: learners and educators alike realise that they can offer positive and valuable contributions to scholarship (Nash 46).

While this approach might be valuable in the classroom, it might not recreate those moments of supreme pleasure associated with the self in Frankenstein. Ever since I began my career, I have always been told about the importance of "student-centred" learning, "an active dynamic process in which connections ... are fostered through dialogue between teacher and students, and students with their peers. (....) Students construct their own meaning by talking, listening, writing, reading, and reflecting on content, ideas, issues and concerns" ("What is Student Centred Learning?" 5). Despite the emphasis on collaboration, the distinctions between educator and learner are rigidly maintained. In most of my classes I am using the experience of listening to and discussing my mesearch and asking my learners to do the same with me. Each lesson is no more or less than an exercise self- and group analysis in which learners employ a variety of verbal and nonverbal strategies - for example, working on their own, creating 
their own activities or dictating the progress of individual lessons. In this environment we are all learners, collaborating on producing individual as well as collaborative SPNs and sharing them in a non-threatening atmosphere. In this kind of atmosphere it might be perfectly possible for someone to experience a moment of inspiration analogous to that of Mary Shelley. In such situations I see myself not as a pedagogue but an andragogue; stimulating learning in myself as well as in my learners. Every moment of learning becomes a potential "aha" moment, where all of us realise that we have found out something about ourselves and our fellow-learners that we did not know before. If we enhance our self-awareness as a result, then we can begin to understand how truly memorable mesearch can be.

Historically the Gothic genre has been identified with a "haunting-tohorrifying" process that problematizes issues of Romanticism and postRomanticm, nationalism and racism, colonisation and post-colonialism, gender and sexuality, and the obscure lines between life and death, sanity and madness (Hogle 1). I have proposed instead that Gothic has the power to stimulate the imagination, and envisage new horizons, both psychological as well as societal. The genre's real strength lies in its capacity to stimulate mesearch to anyone engaged in mesearch, prompting us to rethink our relationship to the worlds we inhabit. I now know for myself that I can never envisage Gothic as I might have done in the past - as represented in Hollywood or Hammer horror films. Rather it has helped me to redefine my relationship to literature by helping me learn something about myself as well as radically redefining my pedagogy.

\section{Works Cited}

The Art of Gothic: Britain's Midnight Hour. BBC Four, 23 Oct, - 7 Nov, 2014. Television.

Hogle, Jerrold E. Introduction. The Cambridge Companion to Gothic Fiction. Cambridge: Cambridge UP., 2002, 1-21. Print.

Lawrence, D.H. Lady Chatterley's Lover. New York: Passerino, 2015. E-book.

Nash, Robert J. Liberating Scholarly Writing: The Power of Personal Narrative. New York: Teachers' College Press, 2004. Print.

Ord, T.J., "Truth and Postmodernism.” Thomasjaywood.com, 19 Nov. 2009. Web. 15 Sep. 2015.

Raw, Laurence. "Mass Civilisation and Minority Culture: The Work of F. R. Leavis." Civilisation and British Culture: Proceedings of the $21^{\text {st }}$ All-Turkey English Literature Conference. Ed. Nursel İçöz. 90-9. Ankara: Middle East Technical University in association with the British Council, 2000. Print.

Raw. Laurence, and Tony Gurr. Adaptation Studies and Learning: New Frontiers. Lanham: Scarecrow, 2013. Print.

Rees, Emma. "Self-Reflective Study: The Rise of 'Mesearch.'” THES 19 Mar. 2015, 3-5. Print. 
Shelley. Mary. Frankenstein, or, the Modern Prometheus. 1818. Ware: Wordsworth, 2005. Print.

Shteyngart. Gary. Little Failure: A Memoir. London: Hamish Hamilton, 2014. E-book. Webber, Richard. "Mesearch.” Psychology Today, Jul. 2008, 33-36. Print.

"What is Student Centred Learning?" Educational Initiative Centre, U. of Westminster, Sep. 2004. Web. 20 Sep. 2016.

Williams, John. Stoner. New York: Vintage, 2012. Print. 